\title{
NUMERICAL AND EXPERIMENTAL STUDY OF THE MECHANICAL RESPONSE OF ALUMINUM FOAMS UNDER COMPRESSIVE LOADING USING CT DATA
}

\author{
Ali A. Mohammadi Nasrabadi, Reza Hedayati, Mojtaba Sadighi \\ Mechanical Engineering Department, Amirkabir University of Technology, Tehran, Iran \\ e-mail:mojtaba@aut.ac.ir
}

\begin{abstract}
Metal foams are relatively novel materials that due to excellent mechanical, thermal, and insulation properties have found wide usage in different engineering applications such as energy absorbers, bone substitute implants, sandwich structure cores, etc. In common numerical studies, the mechanical properties of foams are usually introduced to FE models by considering homogenized uniform properties in different parts of a foamy structure. However, in highly irregular foams, due to complex micro-geometry, considering a uniform mechanical property for all portions of the foam leads to inaccurate results. Modeling the micro-architecture of foams enables better following of the mechanisms acting in micro-scale which would lead to more accurate numerical predictions. In this study, static mechanical behavior of several closed-cell foam samples has been simulated and validated against experimental results. The samples were first imaged using a multi-slice CT-Scan device. Subsequently, experimental compression tests were carried out on the samples using a uniaxial compression testing machine. The CT data were then used for creating micro-scale 3D models of the samples. According to the darkness or brightness of the CT images, different densities were assigned to different parts of the micro-scale FE models of the foam samples. Depending on density of the material at a point, the elastic modulus was considered for it. Three different formulas were considered in different simulations for relating the local elastic modulus of the foam material to density of the foam material at that point. ANSYS implicit solver was used for the simulations. Finally, the results of the FE models based on the three formulas were compared to each other and to the experimental results to show the best formula for modeling the closed-cell foams.
\end{abstract}

Keywords: metal foam, image processing, compression test, Finite Element Method, CT scan

\section{Introduction}

Due to excellent properties such as low weight, high energy absorption capacity, exceptional acoustic and thermal properties, etc., metal foams have received much attention in the last decades. Metal foams usually have densities about 10-60\% of the density of the material they are made of. Different techniques such as vapor electro-deposition on open-cell polymer foam templates, powder metallurgy, hollow sphere consolidation, solidification in open-cell mold, etc. are used for manufacturing metal foams. Metal foams are usually made of aluminum, but other metals such as steel, nickel, titanium, copper, and gold are the other prevalent materials used for making them. Density of foams is usually stated by relative density which is defined as the ratio of density of the foam to density of the material it is made of (Gibson and Ashby, 1998). Foam structures are categorized into two main groups: open-cell and closed-cell (Banhart, 2001) (Fig. 1). In closed-cell foams, the cells are separated from each other by means of thin walls. However, the open-cell foams are made of struts rather than walls and, therefore, the interior parts of the cells are connected to each other. The closed-cell foams usually have higher strength and energy absorption capacity compared to the open-cell foams. 
There is a tremendous number of works on the experimental investigation of mechanical behavior of metal foams under static loading (Andrews et al., 1999; Cao et al., 2006; Gibson, 2000; Meguid and Xue, 2000). However, due to the fact that metal foams are usually made by different manufacturing techniques and conditions, carrying out experimental works on the mechanical behavior of these materials is still valuable.
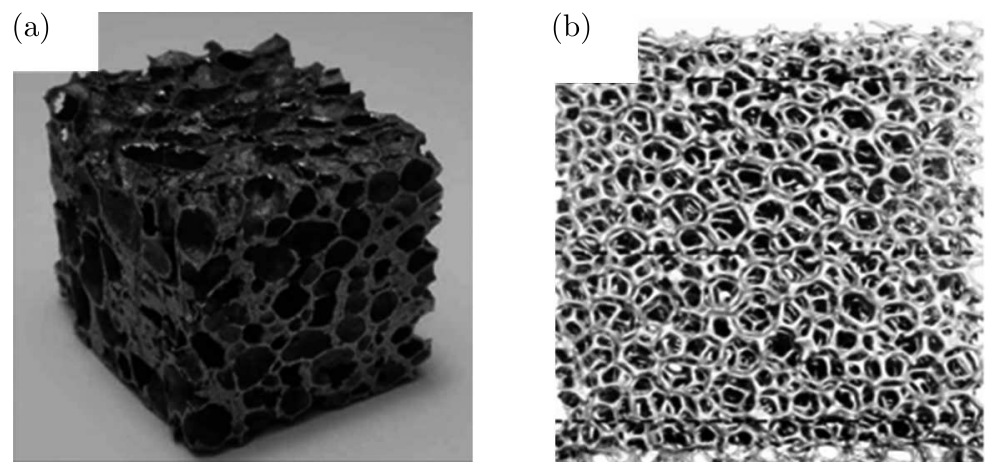

Fig. 1. 1 Different foam types: (a) closed-cell, (b) open-cell

Andrews et al. (1999) compared the compressive and tensile modulus and strength of several aluminum foams to each other and to pure aluminum. Cao et al. (2006) experimentally studied the effect of cell size on compressive properties of open-cell aluminum foams produced by an infiltrating process. They found out that the elastic modulus and compressive strength of this type of foam depends not only on relative density, but also on cell size. Gibson (2000) and Meguid and Xue (2000) also investigated the mechanical behavior of closed-cell foams under different loading conditions.

In an analytical study, Kitazono et al. (2003) derived elastic-plastic properties of closed-cell metal foams using a continuum micro-mechanical model. They also incorporated the effect of gas pressure inside the cells into their calculations. The model was developed to predict the response of both isotropic and anisotropic foams. Their analytical micromechanical model agreed well with the experimental elastic-plastic response of tests samples except for higher density foams. Some other analytical solutions to the mechanical properties of open-cell foams can be found in (Hedayati et al., 2016a,b,c; Ko, 1965).

After the advent of efficient computers, many researchers attempted to model the microstructure of foams by FE (Finite Element) code. There are two main methods in this regard. In the first method (Nammi et al., 2010; Buffel et al., 2014), simple geometrical unit cells were created by the user in such a way that the unit cell shape had the most possible resemblance to the cell shapes of the manufactured foams. Several unit cell types namely Kelvin, Weaire-Phelan, truncated cube, cube, etc. have been proposed for this type of numerical modeling. The unit cell was then repeated several times in the space to create a lattice structure. In the second method, the FE model of the foam was created based on the data obtained from CT-Scan images.

Constructing the FE model using $\mathrm{CT}$ data has been received much attention in the recent years and several studies have been dedicated to it. Youssef et al. (2005) prepared a three-dimensional (3D) model of a polyurethane foam by means of X-ray micro-tomography data. In this regard, the solid volume of the foam was meshed using tetrahedral elements. Using the constitutive equations of the bulk material, a compression test was simulated and the local deformation mechanism of the foams was predicted. Their model was able to correctly capture both the macroscopic response and local deformation mechanisms.

Jeon et al. (2009) fabricated two $5 \mathrm{~mm} \times 5 \mathrm{~mm} \times 5 \mathrm{~mm} \mathrm{Al}$ foam specimens with completely different micro-structures, and numerically analyzed them using a microfocus X-ray CT system, 3D reconstruction program, 3D scanned data processing software, commercial mesh generation 
program, and finally a FE solver. After validating the numerical results, the effects of each mechanical property of the bulk material on the compressive behavior of the foam material was analyzed. In a similar trend, Veyhl et al. (2011) modeled closed-cell and open-cell metal foams using the FE method and investigated the relationship between the foam density and macro-mechanical properties. Their results demonstrated a linear dependence between relative density and mechanical properties of M-Pore ${ }^{\circledR}$ and Alporas ${ }^{\circledR}$ foams. Ramirez et al. (2014) evaluated the elasto-plastic deformation behavior of simulated open-cell foam samples under compressive loads using experimental data. According to the results, the stress-strain distribution and magnitude in the FE model and the experimental testsmatched very well. Using CT data obtained from a compact micro-CT device, Miedzińska et al. (2012) evaluated and described the main mechanisms that appear in the open-cell foam structures during the compression and how they influence the material energy absorbing capabilities. The most important conclusion was that the foam structures can be considered as complex beam constructions where the local instabilities decide about the energy absorbing capabilities. In a more recent study, Zhu et al. (2014) implemented MATLAB image processing toolbar to establish the finite element model of an aluminum foam with porosities of $56.41 \%, 56.71 \%$ and $58.02 \%$. The created FE model was then analyzed using ABAQUS commercial FE code. Comparison with experiments showed the validity of the proposed method of $3 \mathrm{D}$ construction of the model.

In most of the previous micro-geometrical studies on the foam, the local material properties of foams have been considered uniform (and equal to the mechanical properties of the bulk material) in the walls or struts of the foam structure. This assumption is reasonable in foams fabricated by some of the foam manufacturing techniques. However, most of the foams (especially the closed-cell ones) usually do not show uniform material density (and as the result mechanical properties) in their walls or struts. Therefore, considering a uniform mechanical property for all portions of the foam leads to inaccurate results. In this study, the static mechanical behavior of several closed-cell foam samples have been simulated and validated against experimental results. The samples were first imaged using a multi-slice CT-Scan device. Subsequently, experimental compression tests were carried out on the samples using ua niaxial compression testing machine. The CT data were then used for creating 3D models of the samples. According to the darkness or brightness of the $\mathrm{CT}$ images, different densities were assigned to different parts of the FE models of the samples. Depending on density of the material at a point, the elastic modulus was considered for it. Three different formulas were considered in different simulations for relating the elastic modulus to density of the foam material. ANSYS implicit solver was used for carrying out the simulations. In this study, the main goal is to find out which of the three formulas can better follow the mechanical behavior of the foams manufactured by the melting method.

\section{Materials and methods}

\subsection{Experimental technique}

The foams were manufactured by adding $\mathrm{TiH}_{2}$ powders as an foaming agent to the melted aluminum. In molten aluminum (in temperatures about $660^{\circ} \mathrm{C}$ ), $\mathrm{TiH}_{2}$ is decomposed into titanium and hydrogen. The gaseous hydrogen creates bubbles in the molten metal. To stabilize the bubbles, calcium particles are also added to the melted aluminum which increases the viscosity of the molten. After the formation of bubbles, the molten is cooled. Therefore, titanium and calcium materials also exist in the structure of the foam.

Using the abovementioned manufacturing procedure, a $3.2 \mathrm{~mm}$ thick porous plate was created, from which several $30 \mathrm{~mm} \times 30 \mathrm{~mm} \times 32 \mathrm{~mm}$ foam samples were obtained. The foam had some degrees of irregularity due to which the foam samples had average densities between 46$53 \mathrm{~g} / \mathrm{cm}^{3}$, i.e. relative densities in the range of $0.17-0.21$. 
For carrying out the experiments, a uniaxial compression test device (Zwick 1494) was used (Fig. 2). The grip velocity was set to $3 \mathrm{~mm} / \mathrm{s}$. To apply the compressive load uniformly, two steel plates were placed under and above the test samples. The weight of the top steel plate was then taken into account in the load values. Ten samples with geometrical and material specification listed in Table 1 were tested.
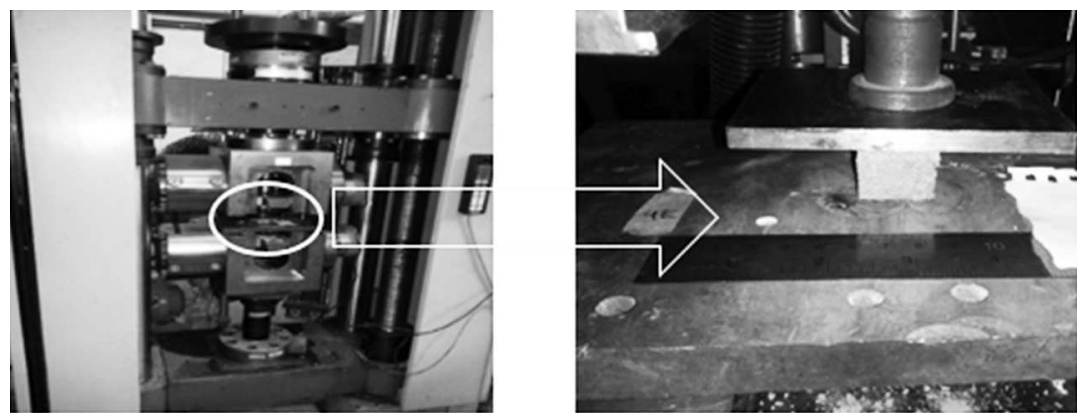

Fig. 2. A specimen in a compression test using the uniaxial compression test machine

Table 1. Geometrical and material properties of ten test samples

\begin{tabular}{|l|c|c|c|c|c|c|c|c|c|c|}
\hline Specimen name & $1 \mathrm{E}$ & $2 \mathrm{E}$ & $3 \mathrm{E}$ & $4 \mathrm{E}$ & $6 \mathrm{E}$ & $3 \mathrm{D}$ & $5 \mathrm{D}$ & $6 \mathrm{D}$ & $5 \mathrm{C}$ & $6 \mathrm{C}$ \\
\hline \hline Mass $[\mathrm{g}]$ & 13.59 & 13.21 & 13.52 & 16.22 & 11.40 & 12.69 & 12.24 & 12.31 & 14.53 & 13.80 \\
\hline Density $\left[\mathrm{g} / \mathrm{cm}^{3}\right]$ & 0.51 & 0.47 & 0.53 & 0.58 & 0.52 & 0.46 & 0.48 & 0.49 & 0.51 & 0.48 \\
\hline Relative density & 0.19 & 0.17 & 0.19 & 0.21 & 0.19 & 0.17 & 0.18 & 0.17 & 0.19 & 0.18 \\
\hline Volume $\left[\mathrm{cm}^{3}\right]$ & 26.48 & 28.08 & 25.35 & 28.17 & 21.84 & 27.32 & 25.61 & 25.36 & 28.61 & 28.53 \\
\hline $\begin{array}{l}\text { Cross-sectional } \\
\text { area }\left[\mathrm{mm}^{2}\right]\end{array}$ & 775 & 824 & 752 & 819 & 666 & 809 & 757 & 818 & 837 & 822 \\
\hline
\end{tabular}

\subsection{Numerical modeling}

All the samples were imaged using Toshiba multi-slice CT scan device (Fig. 3). Four of the ten samples (1E, $2 \mathrm{E}, 3 \mathrm{E}$, and $4 \mathrm{E}$ ) were chosen for numerical modeling. Using the DICOM viewer software, the DICOM images obtained from the CT device were converted into JPEG format which is a suitable format for being read by MATLAB. Using the imread command, the JPEG files were imported into MATLAB. A table matrix was created each row of whichconsisted of the properties of each pixel including the percentage of brightness, relative density, mechanical properties, etc. Generally, in a CT image, the brighter the color of a pixel is, the denser the material at that point is. Therefore, the completely black pixels are representative of pores, while completely white pixels show that density of the foam material at the point is equal to density of the bulk material. A few examples of cross-sections of the constructed finite element models are shown and compared to the corresponding CT images in the test samples in Fig. 4. It must be noted that the arc-shaped part at the bottom of the CT images is not representative of samples, but shows the padding on the CT device bed. These arc-shaped parts were removed from the FE model in the simulations.

According to its brightness, density and elastic modulus values were assigned to each pixel. For each test sample, a 3D cubic structure meshed by cubic brick elements was created and the material properties of the pixels were assigned to the corresponding elements. An example of the 3D model for a sample is shown in Fig. 5. The constructed FE models consisted of about one million brick elements. A high number of elements promises high accuracy of consideration of the material properties gradient inside the foam model. 


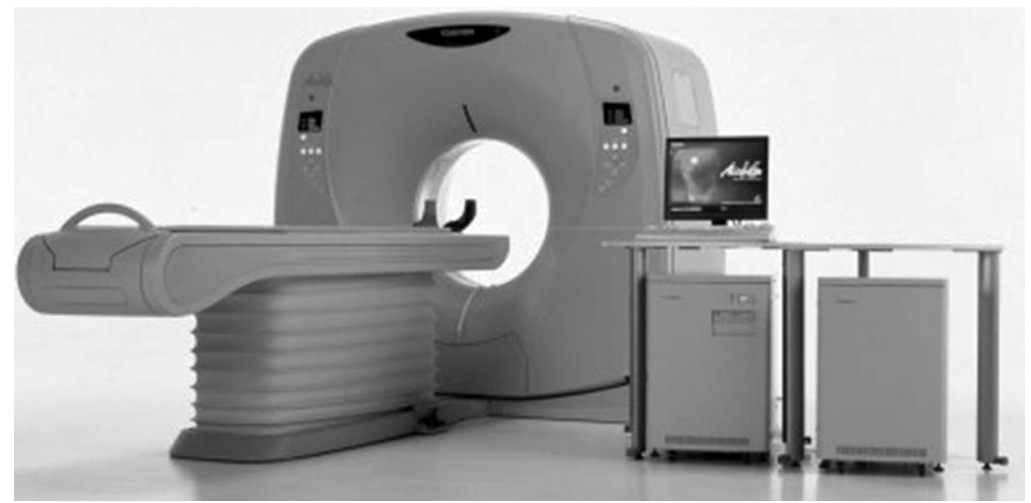

Fig. 3. Toshiba Multi slice 16 CT- Scan device
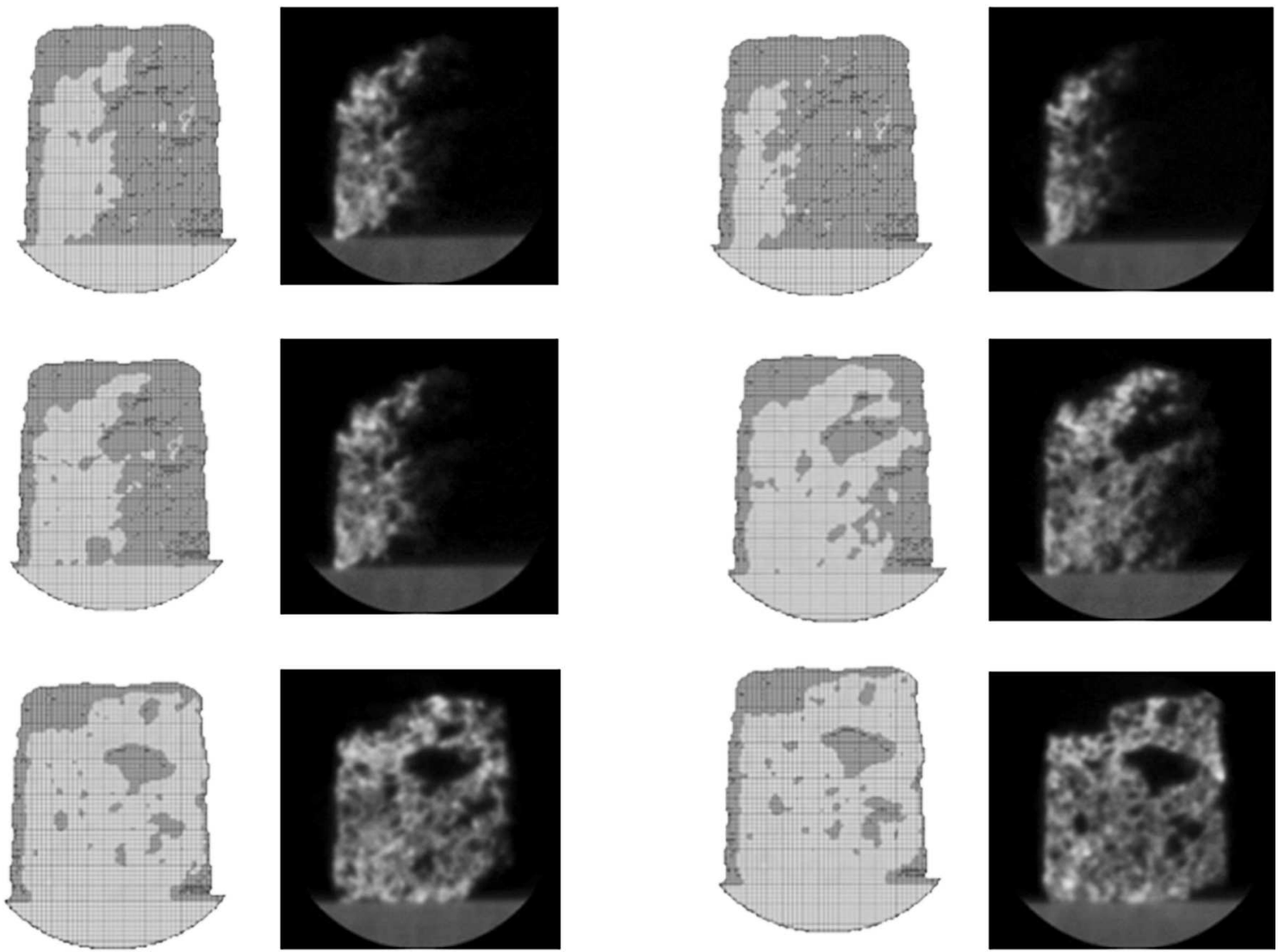

Fig. 4. Reconstructed FE models in ANSYS (left) in comparison with the corresponding CT images (right)

The colors of the CT images (and therefore material density of the foam) were categorized into eleven groups according to the degree of their brightness. The elastic modulus value assigned to each element was not linearly proportional to its density value. Three different nonlinear formulas existing in the literature were implemented for this purpose. Poisson's ratio value was set to 0.3 in all the relative densities. In the first elastic modulus formula, it is assumed that the relative elastic modulus $E / E_{s}$ is proportional to the $n$-th exponent of relative density $\rho / \rho_{s}$, i.e.

$$
\frac{E}{E_{s}}=\left(\frac{\rho}{\rho_{s}}\right)^{n}
$$



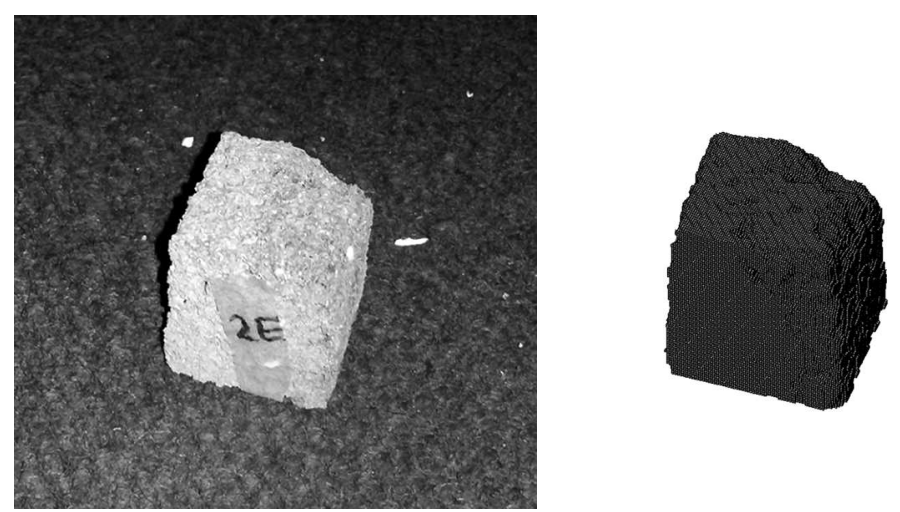

Fig. 5. 3D model of a foam (right) constructed based on the CT data of the test sample (left)

where $E$ and $E_{s}$ are respectively the elastic moduli of the foam material and the bulk material it is made of, and $\rho$ and $\rho_{s}$ are densities of the foam material and the bulk material, respectively. The constant $n$ is obtained by fitting the elastic modulus plots of the FE model and the experiments, which shows that $n=4.4$ gives the best results. This formula is called the $n$-exponential formula in the following. The second formula is based on the relationship proposed by Ashby et al. (2000) for open-cell foams

$$
\frac{E}{E_{s}}=C_{1}\left(\frac{\rho}{\rho_{s}}\right)^{2}
$$

where $C_{1}$ is a constant which must be determined according to experimental/numerical correlation. The best value obtained for $C_{1}$ is 0.02364 . The third formula is the one proposed by Ashby et al. (2000) for closed-cell foams

$$
\frac{E}{E_{s}}=C_{2}\left[\frac{1}{2}\left(\frac{\rho}{\rho_{s}}\right)^{2}+\frac{3}{10} \frac{\rho}{\rho_{s}}\right]
$$

where $C_{2}=0.0151$ yields the best numerical/experimental correlation. The $E / E_{s}$ values assigned to the eleven materials corresponding to the three noted formulations are listed in Table 2 . For a black point (i.e. the locations where there is no material), the elastic modulus $E=1 \mathrm{~Pa}$ is considered which is negligible compared to the elastic moduli of the other parts of the model.

Table 2. Different elastic modulus values assigned to elements of the FE models for the three

\begin{tabular}{|c|c|c|c|c|c|c|c|c|c|c|c|}
\hline & $\frac{E_{1}}{E_{s}}$ & $\frac{E_{2}}{E_{s}}$ & $\frac{E_{3}}{E_{s}}$ & $\frac{E_{4}}{E_{s}}$ & $\frac{E_{5}}{E_{s}}$ & $\frac{E_{6}}{E_{s}}$ & $\frac{E_{7}}{E_{s}}$ & $\frac{E_{8}}{E_{s}}$ & $\frac{E_{9}}{E_{s}}$ & $\frac{E_{10}}{E_{s}}$ & $\frac{E_{11}}{E_{s}}$ \\
\hline $\begin{array}{l}n \text {-exp. } \\
\text { formula } \\
\text { Eq. }(2.1)\end{array}$ & $\begin{array}{l}1.43 \\
\cdot 10^{-11}\end{array}$ & 0.0000 & 0.0008 & 0.0005 & 0.0177 & 0.0474 & 0.1056 & 0.2082 & 0.3746 & 0.6290 & 1.0000 \\
\hline $\begin{array}{l}\text { Open-cell } \\
\text { formula } \\
\text { Eq. }(3.2)\end{array}$ & $\begin{array}{l}1.43 \\
\cdot 10^{-11}\end{array}$ & 0.0002 & 0.0009 & 0.0021 & 0.0038 & 0.0059 & 0.0085 & 0.0116 & 0.0151 & 0.0119 & 0.0236 \\
\hline $\begin{array}{l}\text { Closed-cell } \\
\text { formula } \\
\text { Eq. }(2.3)\end{array}$ & $\begin{array}{l}1.43 \\
\cdot 10^{-11}\end{array}$ & 0.0005 & 0.0012 & 0.0020 & 0.0030 & 0.0042 & 0.0054 & 0.0069 & 0.0085 & 0.0102 & 0.0121 \\
\hline
\end{tabular}
formulas

Large and relatively small pores inside the test samples have also been considered in the constructed models by giving them a very small elastic modulus $(\sim 1 \mathrm{~Pa})$. The hollow space in the periphery of the foam samples are also specified in the FE model in the same way. Very 
small holes (with sizes smaller than the pixel size of the CT images) could not be identified in the CT images. However, these micro pores decrease the brightness of a CT image at the pixel they exist because they decrease the local density of the foam material. Their effect therefore has been incorporated in the FE model by assigning elastic moduli smaller than the elastic modulus of the bulk metal.

Similar to the conditions of the experimental tests, the FE models are constrained in the bottom side and are compressed for $\varepsilon=2 \%$ from the top side. The nodes of the lowermost elements are not allowed to move in the direction parallel to the loading direction but are allowed to move parallel to the bottom surface. To obtain the elastic modulus of each structure $E^{*}$, the total resultant force of the constrained nodes $F$ have been measured and inserted in $E^{*}=F L / \delta A$, where $A$ and $L$ are the cross-section area and length of each sample, respectively. The dimensions of the four samples are listed in Table 3.

Table 3. Dimensions of each of the four samples considered for numerical modeling

\begin{tabular}{|c|c|c|c|}
\hline Specimen & $\delta[\mathrm{mm}]$ & $L[\mathrm{~mm}]$ & $A\left[\mathrm{~mm}^{2}\right]$ \\
\hline \hline $1 \mathrm{E}$ & $0.02 L$ & 34.10 & 775.671 \\
\hline $2 \mathrm{E}$ & $0.02 L$ & 34.06 & 824.600 \\
\hline $3 \mathrm{E}$ & $0.02 L$ & 33.67 & 752.920 \\
\hline $4 \mathrm{E}$ & $0.02 L$ & 34.40 & 819.029 \\
\hline
\end{tabular}

\section{Results and discussion}

\subsection{The experiments}

All the test samples were compressed up to $80 \%$ strain. Knowing the cross-section area and lengths of the samples, the load-displacement curves were converted into stress-strain curves (Fig. 6). For obtaining the elastic modulus of each sample, the slope of the

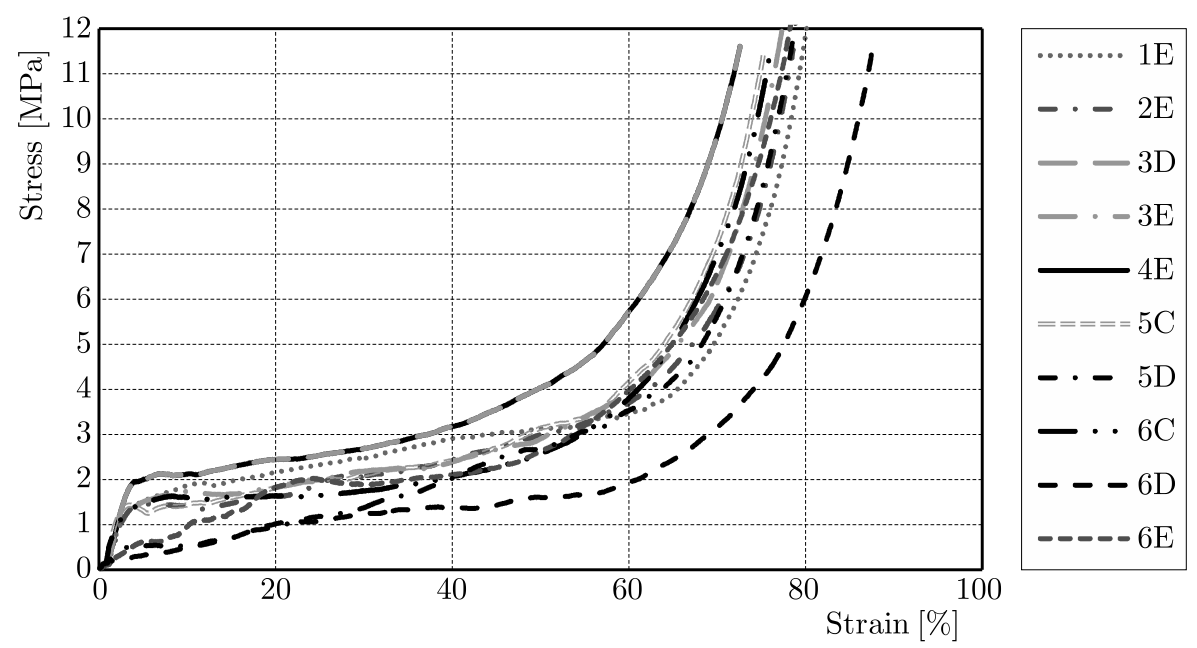

Fig. 6. Experimental stress-strain curves of different Al foam samples under compression

linear part of stress-strain curves is measured (see Fig. 7). The initial parts of the stress-strain curve are neglected in calculating the elastic modulus, because they are associated with the initial micro-plasticity of the uneven surfaces of the foam samples in contact with the grip surfaces. The obtained elastic modulus, plateau stress, densification strain, final elastic modulus and yield stress of the ten samples are listed in Table 4. Due to the presence of large holes created during manufacturing process (e.g. see the large hole in the sample shown in Fig. 8), the specimens 


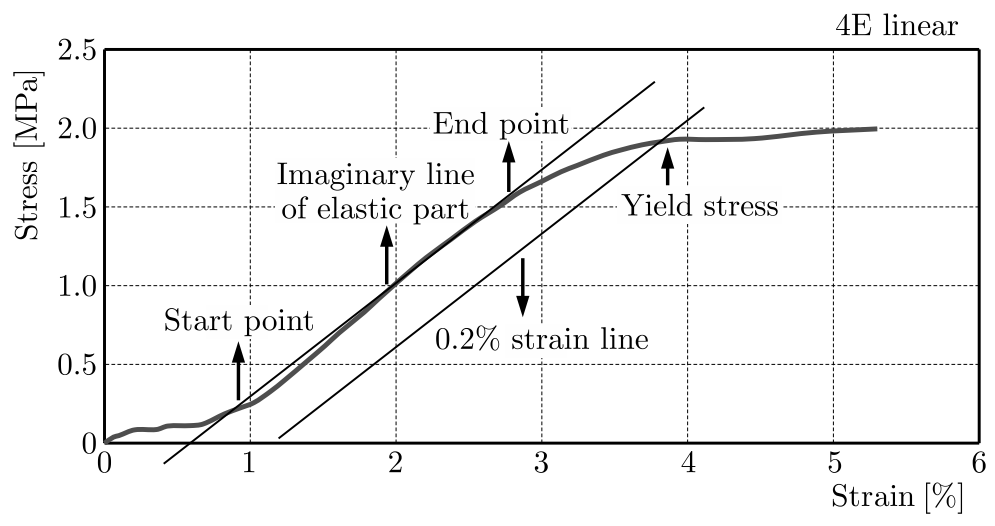

Fig. 7. Linear part of the stress-strain curve of sample $4 \mathrm{E}$

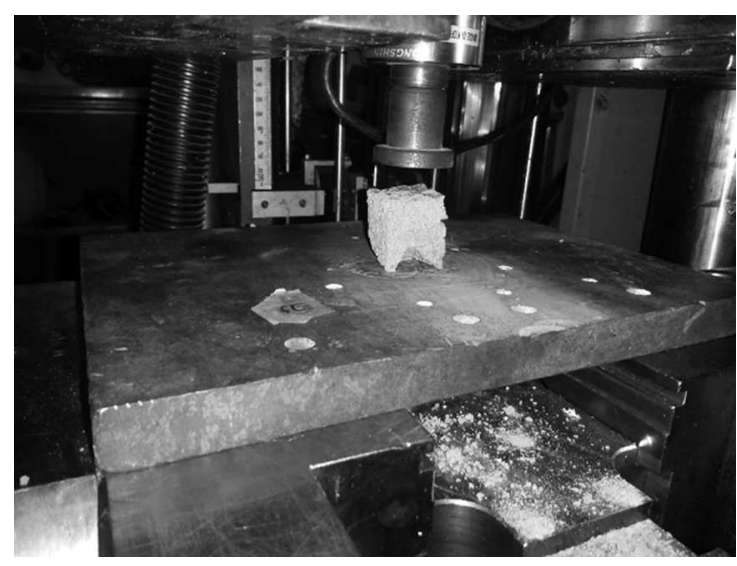

Fig. 8. A large hole in specimen $6 \mathrm{E}$

Table 4. Mechanical properties obtained from compression tests for different specimens

\begin{tabular}{|c|c|c|c|c|c|c|c|c|c|c|}
\hline \multirow{3}{*}{ Specimen } & $1 \mathrm{E}$ & $2 \mathrm{E}$ & $3 \mathrm{E}$ & $4 \mathrm{E}$ & $6 \mathrm{E}$ & $3 \mathrm{D}$ & $5 \mathrm{D}$ & $6 \mathrm{D}$ & $5 \mathrm{C}$ & $6 \mathrm{C}$ \\
\hline & \multicolumn{10}{|c|}{$\mu$} \\
\hline & 0.50 & 0.47 & 0.53 & 0.58 & 0.52 & 0.46 & 0.48 & 0.49 & 0.51 & 0.48 \\
\hline $\begin{array}{l}\text { Elastic } \\
\text { modulus } \\
{[\mathrm{MPa}]}\end{array}$ & 65 & 52 & 77 & 75 & - & 30 & 16.66 & - & 74 & 39 \\
\hline $\begin{array}{l}\text { Plateau } \\
\text { stress } \\
\text { |MPa] }\end{array}$ & $\begin{array}{l}1.7- \\
-3.5\end{array}$ & $\begin{array}{l}1.43- \\
-3.5\end{array}$ & $\begin{array}{c}1.5- \\
-4.01\end{array}$ & $\begin{array}{l}1.93- \\
-4.02\end{array}$ & $\begin{array}{r}1.07- \\
-2.9\end{array}$ & $\begin{array}{c}0.6- \\
-1.8\end{array}$ & $\begin{array}{c}0.53- \\
-2.98\end{array}$ & $\begin{array}{c}1.0- \\
-1.77\end{array}$ & $\begin{array}{c}1.24- \\
-3.14\end{array}$ & $\begin{array}{l}1.56- \\
-2.35\end{array}$ \\
\hline $\begin{array}{l}\text { Densifica- } \\
\text { tion strain } \\
{[\%]}\end{array}$ & 60 & 53.10 & 50.50 & 41.40 & 51.02 & 55.20 & 59.65 & 60 & 56.10 & 50 \\
\hline $\begin{array}{l}\text { Final } \\
\text { el. modulus } \\
{[\mathrm{MPa}]}\end{array}$ & 89.2 & 79.12 & 86.29 & 70.17 & 98.22 & 109.11 & 85.21 & 73.60 & 75.30 & 80.30 \\
\hline $\begin{array}{l}\text { Yield } \\
\text { stress } \\
{[\mathrm{MPa}\rceil}\end{array}$ & 1.41 & 1.46 & 1.41 & 1.96 & - & 0.55 & 0.52 & - & 1.37 & 1.33 \\
\hline
\end{tabular}


$6 \mathrm{E}$ and $6 \mathrm{D}$ do not demonstrate the elastic part in their stress-strain curve and therefore the corresponding cells in Table 4 are left blank.

Table 5. Resultant forces (N) for the four samples and for different formulas

\begin{tabular}{|c|c|c|c|}
\hline Specimen & $\begin{array}{c}\text { Open-cell } \\
\text { formula }\end{array}$ & $\begin{array}{c}\text { Closed-cell } \\
\text { formula }\end{array}$ & $\begin{array}{c}n \text {-exponential } \\
\text { formula }\end{array}$ \\
\hline \hline $1 \mathrm{E}$ & 1024.20 & 1051.97 & 866.58 \\
\hline $2 \mathrm{E}$ & 946.31 & 965.94 & 942.52 \\
\hline $3 \mathrm{E}$ & 1121.10 & 1135.25 & 1147.00 \\
\hline $4 \mathrm{E}$ & 1122.55 & 1045.89 & 1330.74 \\
\hline
\end{tabular}

Table 6. Numerical elastic modulus values for the three formulas compared to the experimental results

\begin{tabular}{|c|c|c|c|c|c|c|c|}
\hline $\begin{array}{c}\text { Speci- } \\
\text { men }\end{array}$ & $\begin{array}{c}\text { Experimen- } \\
\text { tal elastic } \\
\text { modulus } \\
{[\mathrm{MPa}]}\end{array}$ & $\begin{array}{c}\text { FE elastic } \\
\text { modulus based } \\
\text { on open-cell } \\
\text { formula [MPa] }\end{array}$ & $\begin{array}{c}\text { Differ. } \\
\text { with } \\
\text { exper. } \\
{[\%]}\end{array}$ & $\begin{array}{c}\text { FE elastic } \\
\text { modulus based } \\
\text { on closed-cell } \\
\text { formula [MPa] }\end{array}$ & $\begin{array}{c}\text { Differ. } \\
\text { with } \\
\text { exper. } \\
{[\%]}\end{array}$ & $\begin{array}{c}\text { FE elastic } \\
\text { modulus based } \\
\text { on } n \text {-expon. } \\
\text { formula [MPa] }\end{array}$ & $\begin{array}{c}\text { Differ. } \\
\text { with } \\
\text { exper. } \\
{[\%]}\end{array}$ \\
\hline \hline $1 \mathrm{E}$ & 65 & 66.02 & 1.57 & 67.81 & 4.33 & 55.86 & -14.06 \\
\hline $2 \mathrm{E}$ & 52 & 57.38 & 10.36 & 58.57 & 12.63 & 57.15 & 9.90 \\
\hline $3 \mathrm{E}$ & 77 & 74.45 & -3.36 & 75.39 & -2.09 & 76.17 & 1.07 \\
\hline $4 \mathrm{E}$ & 75 & 68.53 & -8.62 & 63.85 & -14.86 & 111.1 & 45.9 \\
\hline
\end{tabular}

As it can be seen in Table 4, the elastic moduli of different samples(with no big hole) are in the range of $16 \mathrm{MPa}$ (for Sample 5D) and $77 \mathrm{MPa}$ (for Sample 3E). The higher average density of the foam is, the larger is the obtainedelastic modulus value. For example, samples $3 \mathrm{E}$ and $4 \mathrm{E}$ which have the highest average densities among all the samples also have the highest elastic moduli. Moreover, these two samples have the highest yield stress and lowest densification strain among all the cases.

Although in the final stages of foam compression, the relative density of the foam samples are close to unity, the elastic modulus in this part is still much smaller than the elastic modulus of the bulk material (about one thousandth), see Table 4. This is because the material particles have lost their continuity and the material layers easily slide on each other.

\subsection{The FE models}

The obtained resultant forces for the four samples and for the three different formulas are listed in Table 5. The obtained elastic modulus values for the three formulas and their difference with experimental results are listed in Table 6. All the numerical results have less than 15\% difference with the experimental data (except the $n$-exponential formula for sample $4 \mathrm{E}$ which has $45.9 \%$ difference with the experiments). The good accordance of the numerical results based on the three formulas demonstrates a proper definition of loading, boundary conditions and discretization of the FE models. Moreover, the results show that the CT-based multi-material foam model, while used with an appropriate density-stiffness formula, can predict the cellular structure mechanical response as well. The results of the open-cell formula give the best numeri$\mathrm{cal} /$ experimental correlation (less than $10.5 \%$ difference), and the closed-cell formula also shows less than $15 \%$ numerical/experimental difference (Table 6).

The stress contour is demonstrated for the four samples in Fig. 9. The stress value is usually higher at locations with higher densities. This correlation between the local material density and stress level is demonstrated in Fig. 10 for cross-section of the foam sample. 

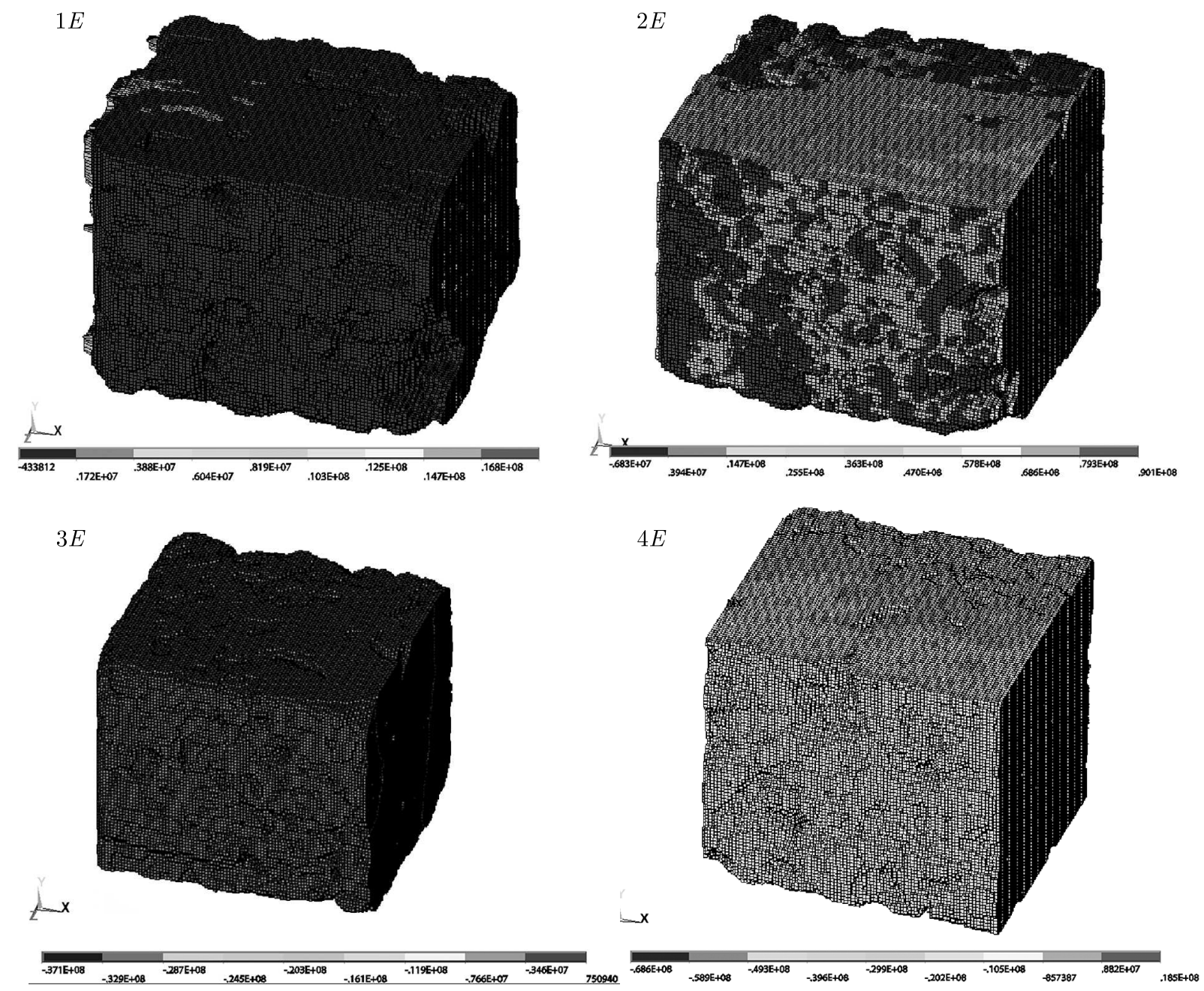

Fig. 9. Stress contour for the four samples

(a)

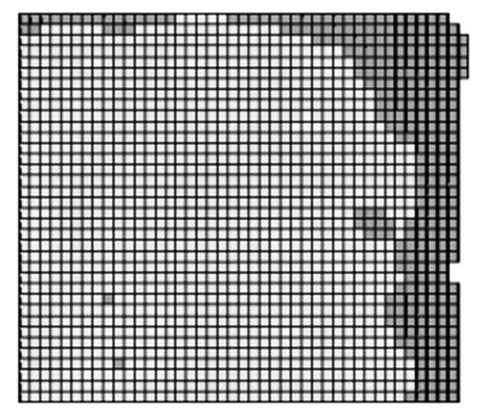

(b)

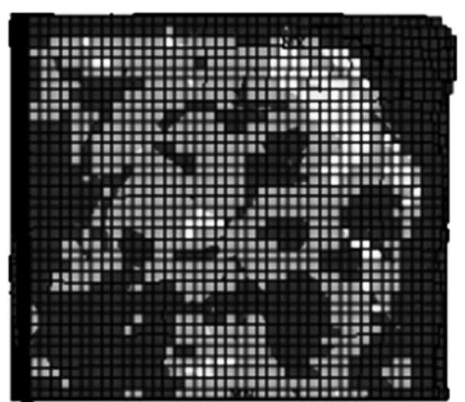

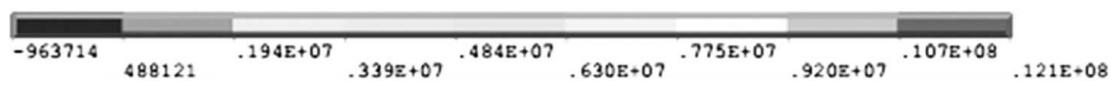

Fig. 10. Comparison of density distribution (left) and stress distribution (right) in a sample

\section{Conclusions}

In this study, the mechanical behavior of aluminum metal foams under compressive static loading is studied experimentally and numerically. For the experimental tests, the elastic modulus, yield stress, plateau stress, densification strain and final elastic modulus have been obtained for ten samples, two of which had large pores. For the numerical modeling, four of the ten samples used in 
the experimental tests were imaged using CT-Scan device before carrying out the experimental tests. The CT data were then used for creating 3D models of the samples. According to the darkness or brightness of the CT images, different densities were assigned to different parts of the FE models of the samples. Three different formulas were considered in different simulations for relating the elastic modulus to density of the foam material. One of the formulas is first presented here (called the $n$-exponential formula), while the two remaining formulas are the relationships proposed by Gibson and Ashby (1998) for open-cell and closed-cell foams. Comparison of the numerical and experimental results demonstrated the superiority of the open-cell formula, in such a way that the numerical/experimental difference is less than $10.5 \%$ for all the samples. The closed-cell formula also shows less than $15 \%$ numerical/experimental difference. For the last formula ( $n$-exponential formula), the numerical/experimental discrepancy is less than $15 \%$ except for one sample which shows an elastic modulus $45.9 \%$ higher than the experimental data. The good accordance of the numerical results based on all the three formulas demonstrates the efficiency of the proposed numerical model methodology. The image processing methodology presented in this paper can therefore be very useful in similar studies.

\section{References}

1. Andrews E., Sanders W., Gibson L.J., 1999, Compressive and tensile behaviour of aluminuim foams, Materials Science and Engineering, A270, 113-124

2. Ashby M.F., Evans A.G., Fleck N.A., Gibson L.J., Hutchinson J.W., Wadley H.N.G., 2000, Metal Foam: a Design Guide, Boston, 978-0-7506-7219-1

3. Banhart J., 2001, Manufacture, characterization and application of cellar metals and metal foams, Materials Science, 46, 559-632

4. Buffel B., Desplentere F., Bracke K., Verpoest I., 2014, Modelling open cell-foams based on the Weaire-Phelan unit cell with a minimal, International Journal of Solids and Structures

5. Cao X.Q., Wang Z.H., Ma H.W., Zhao L.M., Yang G.T., 2006, Effects of cell size on compressive properties of aluminum foam, Transactions of Nonferrous Metals Society of China, 16, $351-356$

6. Gibson L.J., 2000, Mechanical behavior of metallic foams, Annual Review of Materials Science, 30, 191-227

7. Gibson L.J., Ashby M.F., 1998, Cellular Solids, Structure and Properties, UK, Pergamon Press

8. Hedayati R., Sadighi M., Mohammadi-Aghdam M., Zadpoor A.A., 2016a, Mechanical behavior of additively manufactured porous biomaterials made from truncated cuboctahedron unit cells, International Journal of Mechanical Sciences, 106, 19-38

9. Hedayati R., Sadighi M., Mohammadi-Aghdam M., Zadpoor A.A., 2016b, Mechanical properties of regular porous biomaterials made from truncated cube repeating unit cells: Analytical solutions and computational models, Materials Science and Engineering, C60, 163-183

10. Hedayati R., Sadighi M., Mohammadi-Aghdam M., Zadpoor A.A., 2016c, Mechanics of additively manufactured porous biomaterials based on the rhombicuboctahedron unit cell, Journal of the Mechanical Behavior of Biomedical Materials, 53, 272-294

11. Jeon I., Katou K., Sonoda T., Asahina T., Kang K.J., 2009, Cell wall mechanical properties of closed-cell Al foam, Mechanics of Materials, $\mathbf{4 1}$

12. Kitazono K., Sato E., Kuribayashi K., 2003, Application of mean-field approximation to elastic-plastic behavior for closed-cell metal foams, Acta Materialia, 51, 4823-4836

13. Ko W., 1965, Deformations of foamed elastomers, Journal of Cellular Plastics, 1, 45-50 
14. Meguid S.A., Xue H., 2000, On the use of "SDDIS" for measuring deformation localisation in cellular materials, Proceedings of the 3rd International Conference on Mechanics and Materials in Design, Orlando, USA

15. Miedzińska D., Niezgoda T., Gieleta R., 2012, Numerical and experimental aluminum microstructure testing with the use of computed tomography, Computational Materials Science, 64, 90-95

16. NAmmi S.K., Myler P., Edwards G., 2010, Finite element analysis of closed-cell aluminium foam under quasi-static loading, Materials and Design, $\mathbf{3 1}$

17. Ramirez J.F., Cardona M., Velez J.A., Mariaka I., Isaza J.A., Medoza E., Betancourt S., Fernadez-Morales P., 2014, Numerical modeling and simulation of uniaxial compression of aluminum foams using FEM and D-CT images, Procedia Materials Science, 4, 218-222

18. Veyhl C., Belova I.V., Murch G.E., Fiedler T., 2011, Finite element analysis of the mechanical properties of cellular aluminium based on microcomputed tomography, Materials Science and Engineering $A, \mathbf{5 2 8}, 13-14$

19. Youssef S., Maire E., Gaertner R., 2005, Finite element modelling of the actual structure of cellular materials determined by X-ray tomography, Acta Materialia, 53, 719-730

20. Zhu X., Ai S., Fang D., Liu B., Lu X., 2014, A novel modeling approach of aluminum foam based on MATLAB image processing, Computational Materials Science, 82, 451-456 